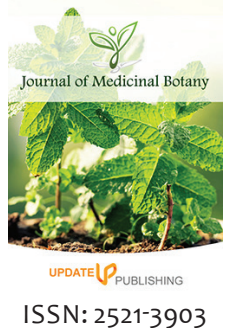

Received: December 11, 2018 Accepted: February 01, 2019 Published: February 09, 2019

\section{*Corresponding Author:} Alev ÖNDER

Email: pharmacogalev@gmail.comKEYWORDS: Antimicrobial, Apiaceae, herbals, MIC, spice

\title{
Evaluation of antimicrobial potential of some spices from Apiaceae sold in herbal shops
}

\author{
Alev ÖNDER ${ }^{1 *}$, Suna Sibel GURPINAR², Müjde ERYILMAZ², \\ Bayram Kağan AKAY', Ahsen Sevde ÇINAR ${ }^{1,3}$ \\ 'Department of Pharmacognosy, Faculty of Pharmacy, Ankara University, Ankara, Turkey, '2Department \\ of Pharmaceutical Microbiology, Faculty of Pharmacy, Ankara University, Ankara, Turkey, ${ }^{3}$ Department of \\ Pharmaceutical Botany/Pharmacognosy, Faculty of Pharmacy, Lokman Hekim University, Ankara, Turkey
}

\begin{abstract}
Spices are used for many purposes such as preservatives and colorants in foods and medicinals in pharmaceutics. The objective of this research was to evaluate the potential antimicrobial activity of some spices from Apiaceae family such as Ammi visnaga (Diş otu, Hiltan), Anethum graveolens (Dereotu), Apium graveolens (Kereviz), Coriandrum sativum (Kişniş), Cuminum cyminum (Kimyon), Daucus carota (Havuç), Foeniculum vulgare (Rezene), Petroselinum sativum (Maydanoz), Pimpinella anisum (Anason). The fruits have been extracted by $n$-hexane, and all extracts have been have been analyzed using Thin Layer Chromatography (TLC). (Thin Layer Chromatography). The $n$-hexane extracts were screened for their potential in vitro antibacterial activity against Staphylococcus aureus ATCC 29213, Enterococcus faecalis ATCC 29212, Escherichia coli ATCC 25922, Klebsiella pneumoniae ATCC 13883, Pseudomonas aeruginosa ATCC 27853 and antifungal activity against Candida albicans ATCC 10231 by microbroth dilution method. The hexane extracts of the fruits of C. sativum, A. graveolens, D. carota, and P. anisum did not show antimicrobial activity against tested microorganisms. Except these, the other extracts having MIC values of $2.5-5-10 \mathrm{mg} / \mathrm{mL}$ exhibited weak antimicrobial effect against tested organisms comparing with the standards. These results demonstrate that the extracts which have an antimicrobial effect can probably play a role as an antimicrobial agent owing to their nonpolar components which are accumulated to the $n$-hexane extracts.
\end{abstract}

\section{INTRODUCTION}

Plants, animals, and microorganisms represent broad sources of natural compounds with medicinal properties extensively investigated and employed in traditional medicine for many years $[1,2]$. Plants are used as dietary supplements and as drug substances; many of them are also used as culinary spices, flavoring agents, and colorants in foods [3]. Egyptians, Chinese, and Indians are often used spices and essential oils since ancient time in folk medicines. Also, the spices can stimulate the secretion of saliva, promote the digestion, prevent from cold and influenza, reduce nausea and vomiting [1]. Spices and herbs have been studied often in different countries because of their high antioxidant activity and for their beneficial effects on human health $[4,5]$. In addition, a diet rich in plant-based agents including spices can prevent most of the chronic diseases. "Spice" derivates from the Latin word, "species," which means a commodity of unique distinction or value [6].
Spices and herbs protect the foods by restricting rancidity through their antioxidant activity or through their bacteriostatic and bactericidal activity as chemical preservatives [7] mostly obtained from aromatic plants $[8,9]$. Therefore, the main objective of this study was to investigate in vitro antimicrobial activity of the extracts from different spices especially from Apiaceae family, as the most important family containing aromatic and flowering plants such as Ammi visnaga (L.) Lam. (Dişotu, hiltan in Turkish; toothpick-plant, toothpick weed, bisnaga, khella, bishop's weed in English), Anetum graveolens L. (Dereotu in Turkish; dill in English), Apium graveolens L. (Kereviz in Turkish; celery in English), Coriandrum sativum L. (Kişniş in Turkish; coriander in English), Cuminum cyminum L. (Kimyon in Turkish; cumin in English), Daucus carota L. (Havuç in Turkish; carrot in English), Foeniculum vulgare Mill. (Rezene in Turkish; fennel in English), Petroselinum sativum Hoffm. (Maydanoz in Turkish; parsley in English), Pimpinella anisum L. (Anason in Turkish; anise in English), and

Copyright: $\odot$ The authors. This article is open access and licensed under the terms of the Creative Commons Attribution License (http://creativecommons.org/licenses/by/4.0/) which permits unrestricted, use, distribution and reproduction in any medium, or format for any purpose, even commercially provided the work is properly cited. Attribution - You must give appropriate credit, provide a link to the license, and indicate if changes were made. 
Table 1. The origin and extract amounts of the selected spices

\begin{tabular}{|c|c|c|c|c|c|}
\hline Plant materials & Turkish name & The fruits amounts (g) & Dried extract $(\mathrm{g})$ & The yield of the extract (\%) & Origin \\
\hline Ammi visnaga L. (Lam.) & Dişotu, Hıltan & 10.00 & 1.47 & 14.7 & Mersin \\
\hline Anethum graveolens L. & Dereotu & 10.01 & 0.89 & 8.9 & Muğla \\
\hline Apium graveolens $\mathrm{L}$. & Kereviz & 10.02 & 1.77 & 17.7 & Çanakkale \\
\hline Coriandrum sativum L. & Kişniş & 10.01 & 1.53 & 15.3 & Konya \\
\hline Cuminum cyminum L. & Kimyon & 10.02 & 2.06 & 20.6 & Karaman \\
\hline Daucus carota L. & Havuç & 10.00 & 1.52 & 15.2 & Ankara \\
\hline Foeniculum vulgare Mill. & Rezene & 10.00 & 1.58 & 15.8 & Muğla \\
\hline Petroselinum sativum Hoffm. & Maydanoz & 10.00 & 1.18 & 11.8 & Antalya \\
\hline Pimpinella anisum $\mathrm{L}$. & Anason & 10.05 & 2.16 & 21.6 & Tekirdağ \\
\hline
\end{tabular}

Table 2. MIC values of some spices marketed in Turkey against tested microorganisms $(\mathrm{mg} / \mathrm{mL})$

\begin{tabular}{lcccccc}
\hline & \multicolumn{7}{c}{ Test microorganisms } \\
\cline { 2 - 7 } & $\mathrm{A}$ & $\mathrm{B}$ & $\mathrm{C}$ & $\mathrm{D}$ & $\mathrm{E}$ & $\mathrm{F}$ \\
\hline Petroselinum sativum & - & - & - & - & - & 10 \\
Coriandrum sativum & - & - & - & - & - & - \\
Ammi visnaga & 2.5 & 2.5 & - & - & 10 & 2.5 \\
Anethum graveolens & - & - & - & - & - & - \\
Daucus carota & - & - & - & & - & - \\
Apium graveolens & 5 & 5 & 10 & 5 & 10 & 2.5 \\
Cuminum cyminum & 10 & - & 10 & 10 & - & 5 \\
Foeniculum vulgare & - & - & - & - & - & 2.5 \\
Pimpinella anisum & - & - & - & - & - & - \\
Ampicillin & 0.0003 & 0.001 & NT & NT & NT & NT \\
Ofloxacin & NT & NT & 0.001 & 0.008 & NT & NT \\
Ciprofloxacin & NT & NT & NT & NT & 0.0625 & NT \\
Fluconazole & NT & NT & NT & NT & NT & 0.001 \\
DMSO (10\%) & - & - & - & - & - & - \\
\hline "In & & & &
\end{tabular}

"- $"$ = represents no activity NT: not tested (A) Staphylococcus aureus ATCC 29213, (B) Enterococcus faecalis ATCC 29212, (C) Escherichia coli ATCC 25922, (D) Pseudomonas aeruginosa ATCC 27853, (E) Klebsiella pneumoniae ATCC 13883, (F) Candida albicans ATCC 10231

to compare the effect with each other for their antimicrobial potency.

\section{MATERIALS AND METHODS}

\section{Plant Materials}

The dried fruits (100 g each) from the Apiaceae family were purchased from the local herbal shop (Ünyazıcı Baharat), and the fruits have been compared the catalogs to check the species of the fruits. Each spice (fruits; $10 \mathrm{~g}$ ) were weighed and crushed in a mill. The scientific name and tested parts of the plants are given in detail in Table 1.

\section{Extraction of Plant Materials}

Each spice (10 g of fruits) was subjected to reflux for 3 hours using $n$-hexane (Boiling point: $\left.68.7^{\circ} \mathrm{C}\right)(150 \mathrm{~mL})$ as an extracting solvent after macerated two days in a dark and cold place. Then, the $n$-hexane extracts were filtrated. In the end, the hexane was evaporated at $35^{\circ} \mathrm{C}$ using a rotary evaporator to obtain the crude extracts. The crude extract was weighed and kept at room temperature (in a cool place) then were stored at $6^{\circ} \mathrm{C}$ in a refrigerator until use.

\section{Thin Layer Chromatography (TLC) Analysis}

All extracts have been subjected to TLC to examine roughly their chromatographic profile. In this method, $n$-hexane: ethyl acetate (8:2) was used as mobile phase and as stationary phase, silica gel $60 \mathrm{~F}_{254}$ (Merck 1.05554.0001) was used. In our method, $\mathrm{H}_{2} \mathrm{SO}_{4}$ :methanol $(1: 1)$ was used as a revelator and the plate was exposed to heating.

\section{Antimicrobial Activity Assay}

Test microorganisms

The $n$-hexane extracts of all spices were screened for their potential in vitro antibacterial activity against Staphylococcus aureus ATCC 29213, Enterococcus faecalis ATCC 29212, Escherichia coli ATCC 25922, Klebsiella pneumoniae ATCC 13883, Pseudomonas aeruginosa ATCC 27853 and antifungal activity against Candida albicans ATCC 10231.

\section{Screening for antimicrobial activity [Minimum inhibitoryconcentrations (MIC)]}

Microbroth dilution method was used for determination of the minimum inhibitory concentrations (MIC) $[10,11]$. The cultures were obtained in Mueller Hinton Broth (Difco, Difco Laboratories, Detroit, MI, USA). Serial two-fold dilutions ranging from 10 to $0.078 \mathrm{mg} / \mathrm{mL}$ were prepared in the medium. A set of wells containing only inoculated broth, 10\% DMSO, ampicillin, ofloxacin, ciprofloxacin, and fluconazole were used as a control. After incubation for $18-24$ h at $37 \pm 1^{\circ} \mathrm{C}$ for bacteria, $48 \mathrm{~h}$ for fungi, the last tube with no microbial growth was recorded to represent MIC value $(\mathrm{mg} / \mathrm{mL})$.

\section{RESULTS AND DISCUSSION}

Spices, herbs, and their constituents are generally recognized as safe (GRAS) and approved by several regulatory agencies new technologies in food preservation lead to less use of preservatives and the use of antimicrobials from the natural sources [12]. In this context, spices appear to be promising natural products due to their antimicrobial effects and the compounds that exhibit this effect. Moreover, spices are going to be important in recent years as potential natural sources of food preservatives. 


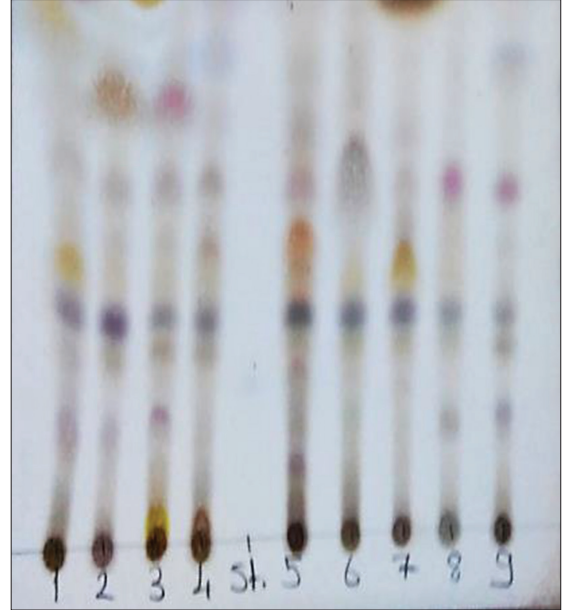

Figure 1: TLC chromatogram in daylight after after the treatment with $\mathrm{H}_{2} \mathrm{SO}_{4}: \mathrm{MeOH}$ reagent then heating at $80^{\circ} \mathrm{C}$

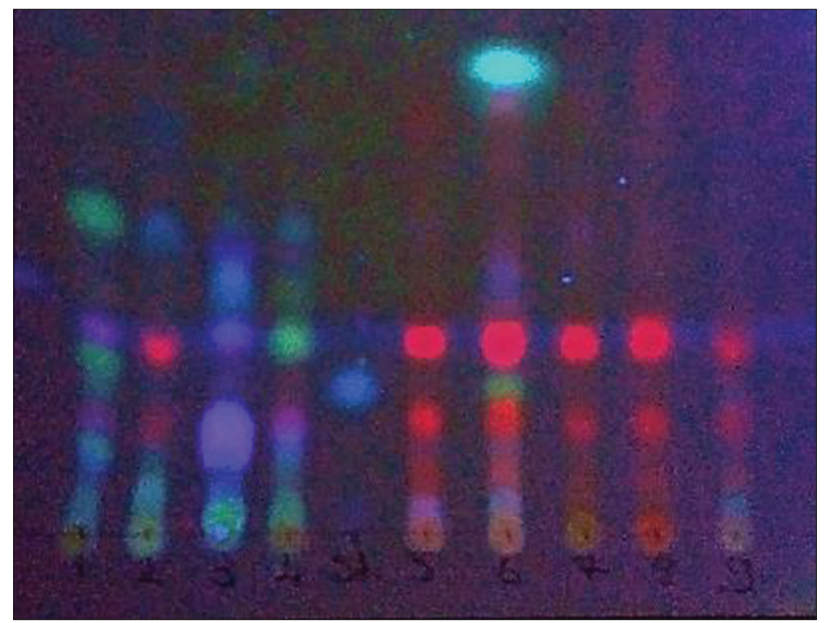

Figure 2: TLC chromatogram under the UV light at $366 \mathrm{~nm}$

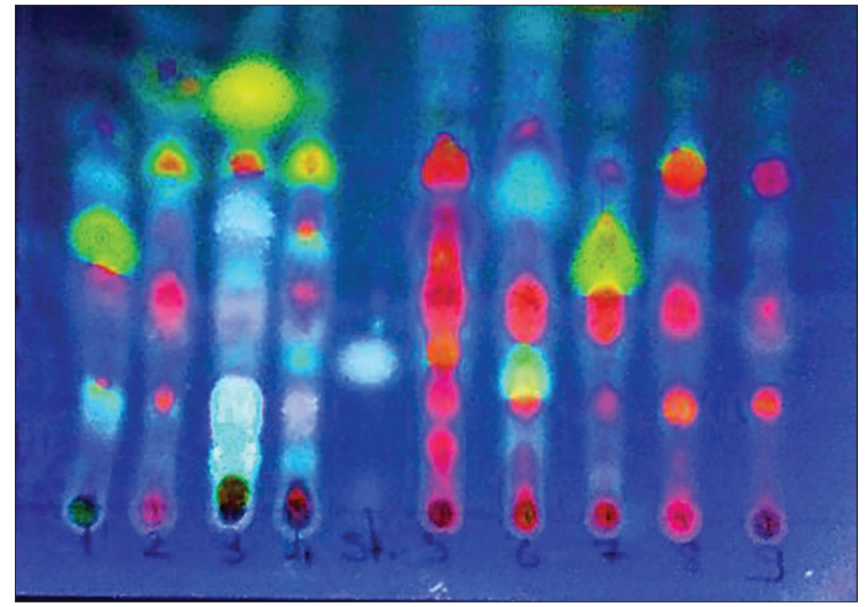

Figure 2: TLC chromatogram under the UV light at $366 \mathrm{~nm}$ after the treatment with $\mathrm{H}_{2} \mathrm{SO}_{4}: \mathrm{MeOH}$ reagent

In the present study, the spices were screened for in vitro antibacterial activity against Staphylococcus aureus ATCC 29213, Enterococcus faecalis ATCC 29212, Escherichia coli
ATCC 25922, Klebsiella pneumoniae ATCC 13883, Pseudomonas aeruginosa ATCC 27853 and antifungal activity against Candida albicans ATCC 10231. Microbroth dilution method was used for determination of the inhibitory concentrations (Table 2). In addition, the extracts have been examined by TLC to determine the chromatographic profile of the spices in the nonpolar solvent (Figures 1-3). The $n$-hexane solvent separates mainly less and low polar components. Thus, less polar coumarin aglycones and terpenic compounds can be found in the extract. The MIC results of the extracts have been shown in Table 2 . The $n$-hexane extracts of the fruits of Coriandrum sativum, Anethum graveolens, Daucus carota, and Pimpinella anisum did not show antimicrobial activity against tested microorganisms. Except for these extracts, the others having MIC values of 2.5$5-10 \mathrm{mg} / \mathrm{mL}$ exhibited antimicrobial effect against some tested microorganisms. Therefore, the nonpolar components which are accumulated into the $n$-hexane extracts may responsible for the antimicrobial effect.

In previous studies, many compounds isolated from spices have antimicrobial activity against some most common microorganisms that affect the food quality and of shelf life $[1,8,9]$. The in vitro antibacterial activity of seven ethanolic extracts of the spices against high-level gentamicin-resistant (HLGR) enterococci isolated from human clinical samples have been investigated. Cinnamomum zeylanicum and Zingiber officinale showed the maximum antibacterial activity against the enterococcal isolates followed by Syzygium aromaticum and Cuminum cyminum [13].

In this study, Ammi visnaga (L.) Lam. (Diş otu, Hıltan), Apium graveolens L. (Kereviz), Cuminum cyminum L. (Kimyon), Foeniculum vulgare Mill. (Rezene), Petroselinum sativum Hoffm. (Maydanoz) demonstrated weak antimicrobial activity.

\section{CONCLUSION}

In conclusion, the plant extracts have great potential as antimicrobial agents. This study provides significant information about antimicrobial activities of $n$-hexane extracts of Petroselinum sativum, Coriandrum sativum, Ammi visnaga, Anethum graveolens, Daucus carota, Apium graveolens, Cuminum cyminum, Foeniculum vulgare, and Pimpinella anisum, which are also used as spice from Apiaceae family. Nonpolar components accumulated into the $n$-hexane extracts of the plants may be responsible for the antimicrobial activity. In addition, aromatic plants contain terpenoids as nonpolar compounds, since most of the spices are fragrant, may have an antimicrobial activity for this reason. In this study, P. sativum, A. visnaga, A. graveolens, C. cyminum, F. vulgare showed antimicrobial activity weakly. As a result of this, maybe the extracts in different solutions of the spices can be investigated for this activity in the future. At this moment, we evaluated on the nonpolar fractions.

\section{ACKNOWLEDGMENTS}

The authors thank Mısır Çarşısı Baharat İth. İhr. Ltd. Şti. for providing and supplying all the spices. 


\section{CONFLICT OF INTEREST}

No conflict of interest was declared by the authors.

\section{REFERENCES}

1. Gottardi D, Bukvicki D, Prasad S, Tyagi AK. Beneficial effects of spices in food preservation and safety. Frontiers in Microbiology. 2016; 7; 1394: 1-20.

2. Hovijitra RS, Choonharuangdej S, Theerathavaj Srithavaj T. Effect of essential oils prepared from Thai culinary herbs on sessile Candida albicans cultures. Journal of Oral Science. 2016; 58: 365-371.

3. Saldanha LG, Dwyer JT, Betz JM. Culinary spice plants in dietary supplement products and tested in clinical trials. Advances in Nutrition. 2016; 7: 343-8.

4. Zheng J, Zhou Y, Li Y, Xu D-P, Li S, Li H-B. Spices for the prevention and treatment of cancers. Nutrients. 2016; 8: 1-35.

5. Yashin A, Yashin Y, Xia X, Nemzer B. Antioxidant activity of spices and their impact on human health: A Review. Antioxidants. 2017; 6: 1-18.

6. Kunnumakkara AB, Sailo BL, Banik K, Harsha C, Prasad S, Gupta SC, Bharti AC, Aggarwal BB. Chronic diseases, inflammation, and spices: how are they linked? Journal of Translational Medicine. 2018; 16: 14.
7. Liu Q, Meng X, Li Y, Zhao C-N, Tang G-Y, Li H-B. Antibacterial and antifungal activities of spices. International Journal of Molecular Sciences. 2017; 18; 1283

8. Naveed R, Hussain I, Tawab A, Tariq M, Rahman M, Hameed S, Mahmood MS, Siddique AB, lqbal M. Antimicrobial activity of the bioactive components of essential oils from Pakistani spices against Salmonella and other multi-drug resistant bacteria. BMC Complementary and Alternative Medicine. 2013; 13: 1-10.

9. Marín I, Sayas-Barberá E, Viuda-Martos M, Navarro C, Sendra E. Chemical composition, antioxidant and antimicrobial activity of essential oils from organic fennel, parsley, and lavender from Spain. Foods. 2016; 5: 1-10.

10. Clinical Laboratory Standards Institute (CLSI) M100-S23; Vol. 33 No.1, January 20133 ISO Standart 20776-1, 2006.

11. European Committee on Antimicrobial Susceptibility Testing (EUCAST). Breakpoint tables for interpretation of MICs and zone diameters. Version 3.1., valid from 2013-02-11.

12. Dhiman R, Aggarwal N, Aneja KR, Kaur M. In vitro antimicrobial activity of spices and medicinal herbs against selected microbes associated with juices. International Journal of Microbiology. 2016; 2016: 1-9.

13. Revati S, Bipin C, Chitra PB, Minakshi B. In vitro antibacterial activity of seven Indian spices against high-level gentamicin-resistant strains of Enterococci. Archives of Medical Science. 2015; 11: 863-868. 